Investigations

\title{
Changes in the Composition and Properties of Meadow Solonchaks of the Ili Alatau Foothill Plain in the Republic of Kazakhstan during a Long Postmeliorative Period
}

\author{
Aigul Kaiyrbekovna Beketova, Saginbay Kaldybaev and Zhainagul Yertayeva \\ Kazakh National Agrarian University, \\ Kazakhstan, 050010, Almaty, Abai Avenue, 8, Kazakhstan
}

\author{
Article history \\ Received: 30-05-2017 \\ Revised: 19-08-2017 \\ Accepted: 13-10-2017 \\ Corresponding Author: \\ Aigul Kaiyrbekovna Beketova \\ Kazakh National Agrarian \\ University, Kazakhstan, \\ 050010, Almaty, Abai Avenue, \\ 8, Kazakhstan \\ Email: beketova.aigul@mail.ru
}

\begin{abstract}
The optimal depth of the groundwater table and the water-salt regime is of importance in the postmeliorative period. The scope of these studies is to provide scientifically grounded assessment of previously reclaimed soils (water irrigation with a total norm of $5000 \mathrm{~m}^{3} /$ ha under conditions of deep horizontal drainage, 1986-1989) in the postmeliorative period of 2015-2016 and to develop parameters for forecasting their meliorative regime. This work was conducted with the use of traditional ground-based methods of soil research. As a result of the research, data were obtained that allow assessing the water-salt regime, groundwater levels, their mineralization, as well as changes in the physical and hydrophysical properties of the previously reclaimed meadow solonchaks under natural conditions and under alfalfa in the background of deep, horizontal drainage and developing soil biota control techniques, including improvement of the meliorative state of the soil and indicators of their effective fertility.
\end{abstract}

Keywords: Secondary Salinization, Collector-Drainage Network, Melioration, Water-Salt Regime, Groundwater Level, Salinity, Desalination, Seasonal Accumulation of Salts, Physical and Hydrophysical Properties, Postmeliorative Period

\section{Introduction}

Throughout the history of the soil science development, saline soils have been one of the main objects of research in many countries of the world. Firstly, this is due to the wide spread of saline soils in different regions of the Earth; secondly, due to the fact that salinity is one of the main genetic properties and meliorative features of soils in arid and semiarid regions and also a property that limits their fertility. Finally, thirdly, salinity is one of the main signs of the unfavorable ecological condition of the soils.

Saline soils are distributed on all continents; they are found in 100 countries of the world and practically in all natural zones, but dominate in the steppes, semi-deserts and deserts. At the same time, in various regions saline soils differ significantly in their properties, genesis and, consequently, in melioration methods, which causes differences in their development, rational use and salinity control (Shishov and Pankova, 2006).

Secondary salinization of irrigated lands brings enormous damage to agriculture. The main reason for this harmful phenomenon is the lack of an engineering collector-drainage network in conditions of weak natural groundwater outflow, which lead to secondary soil salinization and deterioration. Deterioration of the water-salt and nutrient status of soil leads to decrease in the productivity of irrigated land and falling of a part of irrigated arable land out of agricultural turnover (Kovda 2008; Pankova, 2004; Saparov et al., 2014; Berezin et al., 2013; Seelig and Richardson, 1991; Kalinichenko et al., 2011; Pankova and Gerasimova, 2012).

Today, despite the well-studied genesis of saline soils in the southeast of Kazakhstan, the issues of improving saline soils in the sasa belt of the Ili Alatau foothill plain require further development and generation of practical experience in its implementation.

\section{Methods}

The research object were the previously reclaimed (1986-1989) meadow solonchaks of the Ili Alatau foothill plain in the Teskensu farm (Almaty region), where alfalfa (Zhetysusky variety) was sown (in 2015) 
on an area of 2.0 hectares. Irrigation was carried out with an irrigation norm (to humidify $0-50 \mathrm{~cm}$ of the soil layer) of $350 \mathrm{~m}^{3} /$ ha. The total irrigation norm for two years was $2,100 \mathrm{~m}^{3} / \mathrm{ha}$.

In the key areas (under the alfalfa sowing and in the control plot for determining the Seasonal Accumulation of Salts (SAS) at a $200 \mathrm{~m}$ interdrain area) soil samples were taken every $20 \mathrm{~cm}$ to a depth of $1 \mathrm{~m}$ and the following was performed and determined:

- The aqueous extract analysis -by the K.Gedroits method

- Granulometric composition - by pipetting method

- $\mathrm{CO}_{2}$-carbonates -by volumetric method

- Total absorbed bases - by P. Grabarov method

- Total nitrogen - by Kjeldahl

- Gross phosphorus - by K. Ginzburg, G. Shchegolova

- Hydrolyzed nitrogen - by I.Turin

- Nitrates in aqueous extract from fresh soil samples by Grandval-Liazhu and by ion-selective method

- Labile phosphorus and exchange potassium -by B. Machigin in the modification of B. Grabarov

- Bulk weight -by using cutting cylinder

- Specific weight -by V. Faintsimmer (for saline potting soils)

- Total porosity -by calculating bulk and specific weight data

- Minimum water capacity

- Water permeability -by flooding the natural soil using cutting cylinders

- The degree and types of soil salinization -by anionic and cationic composition

- Toxic salts -by calculation according to the methodological recommendations of N. Bazilevich and N. Pankova

Accounting for the alfalfa harvest was carried out on a key site (in three replications) of $4 \times 4$ meters in size with the drying of the green mass to an air-dry state.

The field, stationary and laboratory-analytical methods were used for research.

\section{Results and Discussion}

The salt regime of soils under natural conditions (previously reclaimed, washing at a rate of $5,000 \mathrm{~m}^{3} / \mathrm{ha}$, $200 \mathrm{~m}$ interdrain area) in the annual cycle is subject to considerable change. According to the reserve of salts in a meter stratum, it was formed according to a seasonally irreversible type of salinity.

In the conditions of Kazakhstani sharply continental climate scientific researches are conducted in the springsummer-autumn period, since in winter, when the temperature is $-40^{\circ} \mathrm{C}$, all chemical and biological processes damp out.
Winter-spring abundant soil moistening contributes to the removal of readily soluble salts in groundwater. As a result, lesser amount of salts was found in the soil profile - $28.698 \mathrm{t} /$ ha in a meter stratum (Table 1).

During the summer-autumn period of the first year of research, due to the lowering of soil moisture and the groundwater level, the opposite phenomenon was observed, namely, due to the strong evaporation of moisture and the rising run of salts, the salinization of the soil occurred and in autumn to the greatest extent: The salt reserves in summer were $32,439 \mathrm{t} / \mathrm{ha}$ and in autumn - 86,513 t/ha (2015), which indicated the process of seasonally irreversible salinity.

The $\mathrm{SO}_{4}^{2-}$ and $\mathrm{Ca}^{2+}, \mathrm{Na}^{+}$ions predominated in the composition of salts, indicating a sulfate-calcium-sodium type of salinity. In the spring, the sulfate ion content in the meter layer fluctuated within the range of 0.300 $0.069 \%$ and in the autumn it increased to $1.033-0.075 \%$. The $\mathrm{Ca}^{2+}$ ion increased in the amount from 0.082 to $0.150 \%$ and the $\mathrm{Na}^{+}$ion - from 0.028 to $0.055 \%$ (in the $0-20 \mathrm{~cm}$ layer). Also, because of the greater mobility there were some increases in chloride content - from 0.006 to $0.012 \%$.

Thus, in the seasonal cycles of the salt regime of previously reclaimed meadow solonchak, in the natural conditions the periods of spring desalinization and summer-autumn salinity were observed in the year under study. Since the SAS coefficient was greater than one (2.98), the process of seasonally irreversible salinity had formed in the soil.

Saline regime in the natural conditions (previously not reclaimed virgin land) at a $200 \mathrm{~m}$ interdrain area in the annual cycle on stock of salts in a meter stratum (0$100 \mathrm{~cm}$ ) had also formed on the seasonally irreversible type of salinity.

While the spring reserves of salts amounted to $225.754 \mathrm{t} / \mathrm{ha}$, due to the strong evaporation of moisture and the rising run of salts, salinization of the soil occurred during the summer-autumn period and in autumn to the greatest extent: Salt reserves in the summer amounted to 249,643 and in autumn - 253,292 t/ha (Table 2).

The coefficient of SAS was more than one (1.12), which indicated the process of seasonally irreversible salinity. The $\mathrm{SO}_{4}^{2-}$ and $\mathrm{Ca}^{+2}+, \mathrm{Na}^{+}$ions predominated in the composition of salts, indicating a sulfate-calciumsodium type of salinity. In the spring, the sulfate ion content in the meter layer fluctuated within the range of $0.810-1.205 \%$ and in the autumn it was $1.152-1.200 \%$. $\mathrm{Ca}^{2+}$ ion varied from 0.100 to $0.264 \%$ and the $\mathrm{Na}^{+}$ion from 0.125 to $0.309 \%$. There were also some increases in chloride levels - from 0.017 to $0.093 \%$.

The salt regime of the soil under the alfalfa of the first and second years of life (2015-2016) above the reclaimed meadow solonchak was formed according to the types of seasonally irreversible desalination (Table 3 ). 
Table 1. Dynamics of the salt reserves in the $0-100 \mathrm{~cm}$ layer (t/ha) at a $200 \mathrm{~m}$ interdrain area (2015)

\begin{tabular}{llll}
\hline Spring & Summer & Autumn & SAS coefficient \\
\hline 28.968 & 32.439 & 86.513 & 2.98 \\
\hline
\end{tabular}

Table 2. Dynamics of the salt reserves in the $0-100 \mathrm{~cm}$ layer $(\mathrm{t} / \mathrm{ha})$ at a $200 \mathrm{~m}$ interdrain area (2015) (virgin land, 2016, average for 2 years)

\begin{tabular}{llll}
\hline Spring & Summer & Autumn & SAS coefficient \\
\hline 225.75 & 249.64 & 253.29 & 1.12 \\
\hline
\end{tabular}

Table 3. Dynamics of the salt reserves in the $0-100 \mathrm{~cm}$ layer $(\mathrm{t} / \mathrm{ha})$ in the key area (alfalfa, average for 2 years)

\begin{tabular}{llll}
\hline Spring & Summer & Autumn & SAS coefficient \\
\hline 43.12 & 43.24 & 33.63 & 0.780 \\
\hline
\end{tabular}

Spring stocks of salts constituted $43.12 \mathrm{t} / \mathrm{ha}$ and in the summer growing season there were some decreases in salt reserves in the soils up to $43.24 \mathrm{t} / \mathrm{ha}$. In the autumn seasonal desalinization exceeded seasonal salinization - $33.63 \mathrm{t} / \mathrm{ha}$. The SAS coefficient was 0.78 , which indicated the process of seasonally irreversible desalination.

While at the end of the third year of life of alfalfa (1989) the amount of salts had equaled in the upper 0-40 cm layer to $0.388-0.620 \%$, after a long postmeliorative period (autumn, 2016) it became 0.440-0.397\% (0-40 $\mathrm{cm})$, i.e., some desalinization of these soils occurred during this period.

It should be noted that the pressure supplies of groundwater in the sasa area of the Ili Alatau foothill plain play active role in the resumption of salinization of lands. It is the pressure supply of groundwater that is an inexhaustible supplier of salts to the upper layers of soils and groundwater. These waters have a hydrocarbonatecalcium composition and contain, in addition, small amount of chlorides and sulfates of sodium and magnesium (Kaldybaev, 2014).

The Ili Alatau foothill plain is the richest in water resources region of the Republic of Kazakhstan. The hydrological conditions of the foothill plains are determined by the geological structure features, the intensity and depth of the ruggedness of relief, the ratio of the elements of the thermal and water balances and the interconnection of surface and groundwater (Shvartsev, 2008; 2001; Lebedeva et al., 2015).

As noted by Kovda (1946), Ahmedsafin (1952) and other researchers, the distribution of groundwater in mountain and foothill areas is subject to zoning, directly related to the overall vertical bioclimatic zone. It manifests itself both in the depth of occurrence and thickness of the groundwater flow and in the successive change in the types of waters according to the conditions of feeding and the peculiarities of their chemistry. There are four hydrogeological zones from the mountains to the Ili River: (1) Filtration of surface water and formation of underflow conditions; (2) approach of groundwater to the surface; (3) excretion of groundwater on the surface; and (4) secondary submersion of groundwater. Each zone is characterized only by the inherent to it mineralization of groundwater.

The zone of filtration and formation of the ground flow starts from the tops of the mountains, includes the mountain belt and the upper part of the foothill plains. This part of the territory is composed of proluvial rocks with considerable water permeability. The precipitation, river water and melt water of glaciers and snow, soaking up the soil and penetrating the fissures of loose rocks, create ground water running along the slope incline towards the foothill plain. Thus, this is the area of groundwater alimentation and movement to the foothill plain.

The zone of approach of groundwater to the surface is located in the middle part of the foothill plain. In the central part of the foothill plain on the periphery of the alluvial fan, the ground waters approach the surface and their wedging occurs, forming the so-called sasa band. Here the depth of groundwater is $0.5-5 \mathrm{~m}$, it is poorly mineralized. The total outflow on the slope of the terrain excludes the possibility of a significant increase in the mineralization of groundwater and it usually does not exceed 1-3 $\mathrm{g} \mathrm{L}^{-1}$ and groundwater chemistry is of bicarbonate-calcium type. For groundwater in the foothill plain, the zonality is also marked by the type of chemistry, namely, the hydrocarbonate-calcium slightly mineralized groundwater of the foothills is replaced by the hydrocarbonate-sulphate (calcium and magnesium) sasa band, gradually shifting in the lower parts of the foothill plains to the slightly $\left(3-5 \mathrm{~g} \mathrm{~L}^{-1}\right)$ and medium mineralized (8-11 $\left.\mathrm{g} \mathrm{L}^{-1}\right)$ sulfate-magnesium and sodium waters.

As is known, groundwater has significant influence on the saline soils formation. Therefore, the depth of the groundwater table and the degree of mineralization are among the main factors determining the meliorative state of lands and the entire complex of agro-meliorative measures (Babaev et al., 2015; Dixon et al., 2009).

The groundwater level does not remain constant, but varies seasonally, upon leaching and irrigation and changes not only in their level but also in mineralization (Lebedeva and Kutovaya, 2013; Lyubimova and Novikova, 2016).

Grabovskaya (1954) suggested the notion of a critical regime of groundwater salinizing the soil. The critical regime of groundwater salinity means the depth above which the initial stage of soil salinization takes place at the end of the growing season.

Kovda (1946) established the relationship between the critical depth of the groundwater level and climatic factors using the equation:

$$
I=170+8 t \pm 15
$$


Where:

$I=$ Critical depth $(\mathrm{cm})$

$t=$ Average annual air temperature $\left({ }^{\circ} \mathrm{C}\right)$

It should be noted that the Kovda (1946) formula reflects natural zoning, but does not take into account the physical properties of soils. Therefore, the values of the critical depth calculated by this formula may not coincide with the experimental values for some irrigation areas.

As has been noted earlier, the territory of the experimental Teskensu site is characteristic of the Ili Alatau foothill plain. Here, the slope of the surface from the south to the north is clearly traced, resulting in the groundwater flows from the mountains in the direction of the Ili River.

The average level of groundwater in the spring under the alfalfa was $135 \mathrm{~cm}$ and the mineralization was $5.58 \mathrm{~g} \mathrm{~L}^{-1}$, that is, according to the classification, it is the medium mineralized one. In the summer and autumn, there is slight decrease in the groundwater level-up to $153-162 \mathrm{~cm} \mathrm{-} \mathrm{and} \mathrm{a} \mathrm{decrease} \mathrm{in}$ mineralization to $4.81-5.48 \mathrm{~g} \mathrm{~L}^{-1}$ Table 4 and Fig. 1 .

Apparently, an active role in the postmeliorative period was played by groundwater pressure supplies, since the upward pressure flow often wedged out in the investigated area and had mineralization of about 1-2 $\mathrm{g} \mathrm{L} \mathrm{L}^{-1}$, raised the groundwater level and also reduced its mineralization.

As is known, the physical and water properties of soils, being a function of past soil formation processes, in turn exert great influence on the direction and rate of the subsequent soil-forming process. The use of this provision makes it possible to correctly assess the genetic features of soils and to develop on their basis the most appropriate agro technical and meliorative measures to optimize their fertility.

Therefore, the study of the physical and water properties of the soils under study makes it possible to determine their changes and effectiveness in land reclamation. The following parameters were studied: Bulk weight, specific weight, porosity, Maximum Hygroscopicity (MH), Wilting Point (WP) and minimum Water Capacity (WC).

\section{Bulk Weight}

The bulk density of soil is a very dynamic property in the surface horizons of the soil and is in complex dependence on the mechanical composition, structural state, organic matter content, readily soluble salts, root systems of plants. It undergoes a significant change in irrigation and, especially, in the mechanical treatment of soils.

According to the data of scientists (Sinelnikov, 1954; Atamanyuk, 1968; Dolgov, 1968; Revut and Sokolovskaya, 1970; Ryzhov and Slesareva, 1972;
Bondarev, 1974; Korolev, 1975; Kuznetsov, 1979), it was established that for cultivated plants the optimal one was the density of the arable layer in the range of $1.10-1.35 \mathrm{~g} / \mathrm{cm}^{3}$. With bulk density of soil below or above this limit, the water-air, heat and food regimes of soils deteriorated and the growth, plant development and crop yield were reduced.

As shown by the data of the investigated soils, the upper horizon of $0-40 \mathrm{~cm}(1.19-1.26)$, where the maximum amount of salts and organic substances concentrated, was characterized by the lowest values of bulk weight before leaching. Here sodium salts predominate in the composition of the salts and they are known to have moderate solubility, hygroscopicity and are found in such two forms as the mirabilite $\mathrm{Na}_{2} \mathrm{SO}_{4} * 10 \mathrm{H}_{2} \mathrm{O}$ and tenardite $\mathrm{Na}_{2} \mathrm{SO}_{4} * \mathrm{H}_{2} \mathrm{O}$. The loosening effect on the soil mass influences the transition from one form to another.

Downward along the soil profile, a sharp increase in the bulk density to $1.62 \mathrm{~g} / \mathrm{cm}^{3}$ occurred below the $40 \mathrm{~cm}$ and its addition according to the Kaczynski scale, was estimated as highly compacted one (Kachinsky, 1965) Major leaching, having a desalinizing effect on the soils and potting soils aeration zone, leads to a change in the quantitative and qualitative composition of the salts and consequently, the bulk mass of the soils along the entire profile. The compaction of the upper soil horizons as a result of their desalinization can be explained by the shrinkage of soils associated with the rearrangement of the soil mass (Table 5).

Cultivation of alfalfa on the previously desalinated soils during three years with the irrigation regime of $75 \%$ of WC did not affect the bulk density. In the $85 \%$ of WC option, where higher leaching water regime was maintained, this indicator decreased to $1.31-1.35 \mathrm{~g} / \mathrm{cm}^{3}$. The decrease in the bulk weight also occurred in the lower horizons in comparison with the initial state.

As a result of the major leaching and cultivation of alfalfa culture on the desalinated soil, the bulk density of meadow solonchaks has changed significantly. The soil structureless and loose one in the upper 0-40 cm layer and strongly compacted below $40 \mathrm{~cm}$, acquired normal structure and fairly good density.

After a long postmeliorative period (2016), in the conditions of industrial crops, some thickening of the upper horizons was observed. The bulk weight in the 0 $100 \mathrm{~cm}$ layer was $1.39-1.52 \mathrm{~g} / \mathrm{cm}^{3}$.

\section{Specific Weight}

As is known, the specific weight of the solid phase of soils depends on the mineralogical composition, the content of organic matter and salts in it. As the data show (Table 6), the specific weight of the solid phase of the upper horizons of meadow solonchaks before leaching (1986) was $2.63-2.66 \mathrm{~g} / \mathrm{cm}^{3}$, with an increase with depth to $2.70-2.75 \mathrm{~g} / \mathrm{cm}^{3}$. 


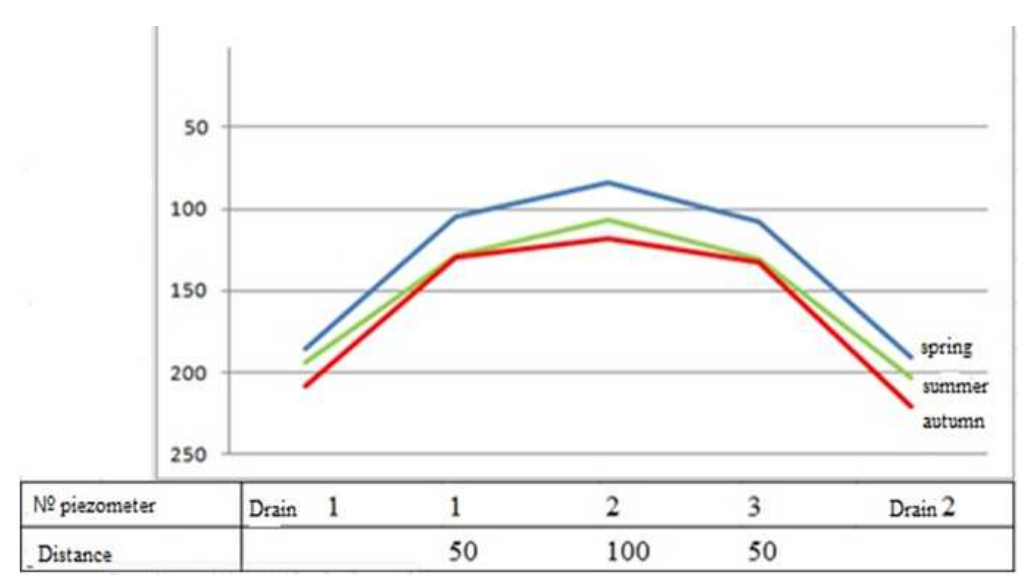

Fig. 1. Dynamics of the groundwater level and mineralization in the experimental plot

Table 4. The dynamics of the groundwater level and mineralization in the experimental plot (alfalfa of the second year of life) at the $200 \mathrm{~m}$ interdrain area, $(\mathrm{cm} / \mathrm{g} / \mathrm{L})$

\begin{tabular}{|c|c|c|c|c|c|c|c|c|}
\hline \multirow[b]{2}{*}{ Years } & \multirow[b]{2}{*}{ Option } & \multirow[b]{2}{*}{ Period } & \multicolumn{5}{|c|}{ Piezometers } & \multirow[b]{2}{*}{ Average value } \\
\hline & & & Drain -1 & 1 & 2 & 3 & Drain - 2 & \\
\hline \multirow[t]{6}{*}{2016} & Key site (alfalfa) & Spring & 186 & 105 & 84 & 108 & 191 & 135 \\
\hline & & & 8.684 & 5.120 & 4.035 & 4.850 & 5.195 & 5.58 \\
\hline & & Summer & 194 & 128 & 107 & 131 & 203 & 153 \\
\hline & & & 6.855 & 5.110 & 3.870 & 4.010 & 4.240 & 4.81 \\
\hline & & Autumn & 208 & 129 & 118 & 133 & 221 & 162 \\
\hline & & & 7.790 & 5.850 & 3.980 & 4.750 & 5.040 & 5.48 \\
\hline
\end{tabular}

Table 5. Change in the bulk weight of meadow solonchak under the influence of meliorative methods, $\mathrm{g} / \mathrm{cm}^{3}$

\begin{tabular}{llllll}
\hline & & \multicolumn{3}{c}{ After 3 years of alfalfa cultivation (1989) } \\
Depth, cm & Before leaching (1986) & After leaching (1987) & 75\% of WC & $85 \%$ of WC & Postmeliorative period (2016) \\
\hline $0-20$ & 1.19 & 1.35 & 1.36 & 1.31 & 1.39 \\
$20-40$ & 1.26 & 1.39 & 1.38 & 1.35 & 1.40 \\
$40-60$ & 1.53 & 1.47 & 1.42 & 1.43 & 1.44 \\
$60-80$ & 1.56 & 1.53 & 1.50 & 1.49 & 1.50 \\
$80-100$ & 1.60 & 1.58 & 1.56 & 1.53 & 1.52 \\
\hline
\end{tabular}

Table 6. Change in the specific weight of meadow solonchak under the influence of meliorative methods, $\mathrm{g} / \mathrm{cm}^{3}$

\begin{tabular}{llllll}
\hline & \multicolumn{4}{c}{ After 3 years of alfalfa cultivation (1989) } \\
Depth, cm & Before leaching (1986) & After leaching (1987) & $75 \%$ of WC & $85 \%$ of WC & Postmeliorative period (2016) \\
\hline $0-20$ & 2.63 & 2.69 & 2.69 & 2.59 & 2.61 \\
$20-40$ & 2.66 & 2.71 & 2.72 & 2.61 & 2.66 \\
$40-60$ & 2.70 & 2.72 & 2.73 & 2.68 & 2.70 \\
$60-80$ & 2.75 & 2.73 & 2.71 & 2.71 & 2.72 \\
$80-100$ & 2.72 & 2.73 & 2.71 & 2.73 & 2.74 \\
\hline
\end{tabular}

Under the influence of leaching and cultivation of alfalfa, change in soil is observed: After leaching an increase in the upper horizons $\left(2.69-2.71 \mathrm{~g} / \mathrm{cm}^{3}\right)$ is observed, which is possibly due to weighting of the mechanical composition and compaction of the soil profile after leaching.

During the development period (under the alfalfa of the 3rd year of life), a decrease in the specific mass of the soil to $2.59-2.61 \mathrm{~g} / \mathrm{cm}^{3}$ is observed in the upper horizons (in the $85 \%$ WC option).
Some decrease in the specific weight after leaching occurs during the developmental period under alfalfa and mainly in the upper, more humus horizons due to the increase in crop residues and root mass of alfalfa.

Determination of the specific weight of the soil after a long postmeliorative period showed that it was further reduced in the $0-40 \mathrm{~cm}$ layer to $2.57-2.59 \mathrm{~g} / \mathrm{cm}^{3}$. Apparently, this was due to an increase in the amount of organic substances (humus-2.98\%) and crop residues. 


\section{Soil Porosity}

Porosity determines many properties of the soil moisture capacity, capillary rise and evaporation of moisture, movement of moisture, nutrients and salts in the soil, availability of moisture to plants, air content in the soil, effective volume of plant root systems development and vital activity of microorganisms.

According to the bulk and specific weight values, the total porosity of the soil before leaching (1986) in the 0-40 cm layer was 54.8-52.6\% (Table 7), in the lower layers it decreased to $43.4-41.2 \%$ and therefore it was assessed as unsatisfactory one.

After leaching and in the cultivation of alfalfa during the developmental period (1989) and also after a long postmeliorative period (2015) in the conditions of production crops, a slight decrease in the total porosity in a meter layer - 47.3-44.5\% - was observed, which correlated with an increase in the bulk weight of the soil.

\section{Maximum Hygroscopicity (MH)}

Soil moisture in the maximum hygroscopicity state is tightly bound and moves in the form of steam and therefore does not dissolve salts, is completely inaccessible to plants and represents a "dead stock" (Dolgov, 1968; Doyarenko, 1963; Rode, 1952; 1966).

The $\mathrm{MH}$ value in the soil profile before leaching (1986) varied within the range of 7.25-4.96\%. Some increase in $\mathrm{MH}$ in the upper horizons in comparison with the underlying layers was explained by higher content of humus and water-soluble salts in the soil. The moisture reserve corresponding to $\mathrm{MH}$ was $838.3 \mathrm{~m}^{3} /$ ha before leaching in the upper meter layer and after washing (1987) its value was $6.37-4.73 \%$ with the moisture reserve of $785.2 \mathrm{~m}^{3} / \mathrm{ha}$ in the upper meter layer. It should be assumed that leaching reduces the value of soil $\mathrm{MH}$, because of the washing out of readily soluble hygroscopic salts. Thus, according to Umarov (1974), an increase in the degree of salinity of the soil to 1 or more percent on a dense residue increases MH 2 times compared with its values in soils leached from salts.

In the development period - under the alfalfa of the 3rd year of life - there was a slight decrease in the MH value and on the $85 \%$ of WC option it was more noticeable than on the $75 \%$ of WC option (in the $0-20$ $\mathrm{cm}$ layer, 5.20 and $5.65 \%$, respectively) and in the postmeliorative period the MH value constituted $5.01 \%$.

Absolutely inaccessible to plants moisture reserve, i.e. its dead stock in the upper meter layer of the soil, was 646.5 and $709.5 \mathrm{~m}^{3} / \mathrm{ha}$ and after a long postmeliorative period $-641.10 \mathrm{~m}^{3} / \mathrm{ha}$.

\section{Wilting Point (WP)}

The plants wilting point depends on the genetic properties of soils, the type of plants and the phases of their development. In terms of accessibility to plants, soil moisture of WP category refers to the hard-to-reach one, which consists of the maximum content of firmly bound and partially loosely bound moisture.

The WP value is the boundary between the available and unavailable soil moisture for the plants. With a decrease in soil moisture to the WP value, the physiological and biochemical processes of plants disturb, their growth stops, wilting and even death begin.

Before leaching (1986), the WP magnitude of plants in the upper meter layer fluctuated within 9.71-6.64\%, which corresponded to a reserve of moisture unavailable to plants of $1141.8 \mathrm{~m}^{3} / \mathrm{ha}$.

After leaching (1987), the WP index slightly decreased to $8.53-6.34 \%$ in the upper meter layer, which in terms of the reserve was equal to $1,051.7 \mathrm{~m}^{3} / \mathrm{ha}$. Under the alfalfa of the 3rd year of cultivation (1989), the WP magnitude of the plant due to some desalinization of the soil profile decreased noticeably and in the upper meter layer it fluctuated at the $75 \%$ of WC option in the range of 7.57-5.96 and in the $85 \%$ of WC option - in the range of $6.97-5.53 \%$, with the relevant reserves in the upper meter layer of 950.6 and $865.8 \mathrm{~m}^{3} / \mathrm{ha}$ and in the postmeliorative period - of $859.2 \mathrm{~m}^{3} / \mathrm{ha}$.

Thus, upon salts leaching from the soil profile during the development period, the values of $\mathrm{MH}$ and the inaccessible moisture decrease and the interval of available moisture for plants increases.

\section{Minimum Water Capacity (WC)}

As is known, the minimum WC characterizes the maximum amount of moisture that the soil can retain in itself in a suspended and equilibrium state after its abundant moistening and free flow of gravitational moisture. It is the most important agronomic and soilhydrogeological constant, on the basis of which all calculations of soil moisture reserves are carried out, including those in terms of its part accessible to the plants, leaching norms, irrigation regime, etc.

The WC value, according to the classification of Rode (1956), refers to the form of free suspended moisture and by accessibility for plants - to the category of easily accessible ones. The minimum WC consists of a sum of firmly bound, loosely bound and capillarysuspended moisture.

The papers of scientists established (Panfilov, 1973; Lusevics, 1980) that the WC value depended on the granulometric composition, humus content, bulk density, salinity, micro- and macrostructure, soil porosity, etc.

In the soils studied by us, the WC value before leaching (1986) fluctuated in the upper meter layer within $23.53-22.56 \%$ of the soil weight.

After leaching, some increase was observed up to $26.50-24.10 \%$ and after 3 years of alfalfa cultivation its value was even higher - $27.25-25.30 \%$ and in the postmeliorative period (2016) in a meter layer it was in the range of $27.04-25.91 \%$ (Table 8). 
Table 7. Change in the general porosity of meadow solonchak under the influence of meliorative methods (\%)

\begin{tabular}{llllll}
\hline & & \multicolumn{3}{c}{ After 3 years of alfalfa cultivation (1989) } \\
Depth, cm & Before leaching (1986) & After leaching (1987) & 75\% of WC & $85 \%$ of WC & Postmeliorative period (2016) \\
\hline $0-20$ & 54.8 & 49.8 & 49.5 & 49.6 & 46.7 \\
$20-40$ & 52.6 & 48.7 & 49.3 & 48.3 & 47.3 \\
$40-60$ & 43.4 & 46.0 & 48.0 & 46.7 & 46.6 \\
$60-80$ & 43.3 & 44.0 & 44.7 & 45.1 & 44.8 \\
$80-100$ & 41.2 & 42.2 & 42.5 & 44.0 & 44.5 \\
\hline
\end{tabular}

Table 8. Changes in the water properties of meadow solonchak and moisture reserves of different categories under the influence of meliorative methods, $\% / \mathrm{m}^{3} /$ ha

\begin{tabular}{|c|c|c|c|c|c|c|c|c|c|c|c|c|c|c|c|}
\hline \multirow{3}{*}{$\begin{array}{l}\text { Depth, } \\
\mathrm{cm}\end{array}$} & \multirow{2}{*}{\multicolumn{3}{|c|}{ Before leaching (1986) }} & \multirow{2}{*}{\multicolumn{3}{|c|}{ After leaching (1987) }} & \multicolumn{6}{|c|}{ After 3 years of alfalfa cultivation (1989) } & & & \\
\hline & & & & & & & \multicolumn{3}{|c|}{$75 \%$ of $\mathrm{WC}$} & \multicolumn{3}{|c|}{$85 \%$ of $\mathrm{WC}$} & \multicolumn{3}{|c|}{ Postmeliorative period (2016) } \\
\hline & MH & WP & WC & MH & WP & WC & MH & WP & WC & MH & WP & WC & MH & WP & WC \\
\hline \multirow[t]{2}{*}{$0-20$} & 7.25 & 9.71 & 23.29 & 6.37 & 8.53 & 26.50 & 5.65 & 7.57 & 26.77 & 5.20 & 6.997 & 27.25 & 5.01 & 6.72 & 27.04 \\
\hline & 172.50 & 231.10 & 554.30 & 171.90 & 230.30 & 715.50 & 153.60 & 205.90 & 728.10 & 136.20 & 182.600 & 713.90 & 137.25 & 184.09 & 740.92 \\
\hline \multirow[t]{2}{*}{$20-40$} & 6.35 & 8.51 & 22.74 & 5.46 & 7.31 & 25.60 & 5.24 & 7.02 & 26.30 & 4.83 & 6.470 & 26.80 & 5.03 & 6.74 & 27.02 \\
\hline & 160.00 & 214.40 & 573.00 & 151.80 & 203.20 & 711.70 & 144.60 & 193.70 & 725.80 & 130.40 & 174.600 & 723.60 & 137.74 & 184.64 & 740.18 \\
\hline \multirow[t]{2}{*}{$40-60$} & 5.89 & 7.89 & 22.56 & 5.33 & 7.14 & 24.77 & 4.59 & 6.15 & 25.91 & 4.22 & 5.650 & 26.07 & 3.95 & 5.30 & 27.10 \\
\hline & 180.20 & 260.40 & 690.30 & 156.70 & 209.90 & 728.20 & 130.30 & 174.60 & 735.80 & 120.60 & 161.500 & 745.60 & 108.35 & 145.24 & 743.48 \\
\hline \multirow[t]{2}{*}{$60-80$} & 5.35 & 7.16 & 23.53 & 5.08 & 6.80 & 24.10 & 4.74 & 6.35 & 25.30 & 4.46 & 5.970 & 25.90 & 4.42 & 5.93 & 26.56 \\
\hline & 166.90 & 223.40 & 734.10 & 155.40 & 208.00 & 737.40 & 142.20 & 190.50 & 759.00 & 132.90 & 177.900 & 771.80 & 130.12 & 174.47 & 781.23 \\
\hline \multirow[t]{2}{*}{$80-100$} & 4.96 & 6.64 & 23.40 & 4.73 & 6.34 & 25.06 & 4.45 & 5.96 & 25.48 & 4.13 & 5.530 & 25.56 & 4.19 & 5.60 & 25.91 \\
\hline & 158.70 & 212.50 & 748.80 & 149.40 & 200.30 & 791.90 & 138.80 & 185.90 & 793.10 & 126.40 & 169.200 & 782.10 & 128.95 & 172.54 & 794.30 \\
\hline $0-100$ & 838.30 & 1141.80 & 3300.50 & 785.20 & 1051.70 & 3684.70 & 709.50 & 950.60 & 3741.80 & 646.50 & 865.800 & 3737.00 & 641.10 & 859.22 & 3799.78 \\
\hline
\end{tabular}

In terms of the stock the WC easily accessible for plants in the upper meter layer was: Before leaching $3,300.5$, after leaching- $3,684.1 \mathrm{~m}^{3} / \mathrm{ha}$; after 3 years of cultivation of alfalfa on the $75 \%$ of WC option with irrigation regime it was equal to $3,741.8$ and on the $85 \%$ of WC - to $3,737.0 \mathrm{~m}^{3} /$ ha. After a long postmeliorative period, the moisture reserve was $3,799.8 \mathrm{~m}^{3} /$ ha.

Thus, as the data show, the desalinization of meadow solonchaks favorably influences the amount of freely available moisture, namely, it improves the supply of agricultural plants with readily available moisture, since in the course of development the $\mathrm{MH}$ decreases and the soil WC increases and, according to the Kachinsky (1965), it passes from the unsatisfactory category into a satisfactory one.

\section{Conclusion}

Thus, in the seasonal cycles of the salt regime of the previously reclaimed meadow solonchak, in the natural conditions the periods of spring desalinization and summer-autumn salinity were observed in the year under study. Since the SAS coefficient was greater than one (2.98), the process of seasonally irreversible salinity had been forming in the soil. The salt regime of the soil under the alfalfa of the first and second years of life (2015-2016) above the reclaimed meadow solonchak was formed according to the types of seasonally irreversible desalination.
The average level of groundwater in the spring under the alfalfa was $135 \mathrm{~cm}$ and the mineralization was $5.58 \mathrm{~g} \mathrm{~L}^{-1}$, that is, according to the classification, it was the medium mineralized one. In the summer and autumn there was a slight decrease in the water table to $153-162 \mathrm{~cm}$ and a decrease in mineralization - to 4.81$5.48 \mathrm{~g} \mathrm{~L}^{-1}$, since the upward flow was often wedged out in the study area and, having mineralization of about 1$2 \mathrm{~g} \mathrm{~L}^{-1}$, raised the groundwater level and also reduced its mineralization.

After a long postmeliorative period (2016), in the conditions of industrial crops, some thickening of the upper horizons was observed. The bulk weight in the $0-100 \mathrm{~cm}$ layer was $1.39-1.52 \mathrm{~g} / \mathrm{cm}^{3}$. Determination of the specific weight of the soil after a long postmeliorative period showed that it was further reduced in the $0-40 \mathrm{~cm}$ layer to $2.57-2.59 \mathrm{~g} / \mathrm{cm}^{3}$. Apparently, this was due to an increase in the amount of organic substances (humus - 2.98\%) and crop residues. Absolutely inaccessible to plants moisture reserve, i.e., its dead stock in the upper meter layer of the soil, was 646.5 and $709.5 \mathrm{~m}^{3} / \mathrm{ha}$ and after a long postmeliorative period - $641.10 \mathrm{~m}^{3} /$ ha. Upon salts leaching from the soil profile during the development period, the values of $\mathrm{MH}$ and the inaccessible moisture decreased and the interval of available moisture for plants increased. After a long postmeliorative period, the moisture reserve was $3,799.8 \mathrm{~m}^{3} /$ ha. Thus, according to N. Kaczynski's grading scale, the soil WC passed from the unsatisfactory category into a satisfactory one. 


\section{Acknowledgments}

The work is carried out within the framework of the grant project: "To study the dynamics of the water-salt regime of meadow solonchak of sasa strips of Ili Alatau piedmont plains by continuous post-reclamation period and to develop scientifically based forecasting parameters of their change" of the Ministry of Education and Science of the Republic of Kazakhstan.

\section{Author's Contributions}

All authors equally contributed in this work.

\section{Ethics}

This article is original and contains unpublished material. The corresponding author confirms that all of the other authors have read and approved the manuscript and no ethical issues involved.

\section{References}

Ahmedsafin, U.M., 1952. On the classification of ground water regime in irrigation areas. Vestnik, 2: 56-61.

Atamanyuk, A.K., 1968. Optimal density of the arable layer of chernozem soils of Moldavia for cereals. Theoretical Problems Soil Treat.

Babaev, M.P., E.A. Gurbanov and F.M. Ramazanova, 2015. Main types of soil degradation in the kuraaras lowland of Azerbaijan. Eurasian Soil Sci., 48: 445-456.

Berezin, L.V., A.S. Saparov, V.M. Kan and M.R. Shayakhmetov, 2013. Technology of Complex Reclamation of Ecosystems in Russia and Kazakhstan. 1st Edn., Printing and Service Ko, Almaty-Omsk, pp: 215.

Bondarev, A.G., 1974. The main features of the addition of soils as the basis for the creation of optimal regimes. Proceedings of the 10th International Congress of Soil Scientists, (CSS' 74), pp: 159-164.

Dixon, J.C., A.J. Parsons and A.D. Abrahams, 2009. Aridic Soils, Patterned Ground and Desert Pavements. 1st Edn., Springer, Geomorphology of Desert Environments.

Dolgov, S.I., 1968. The Study of the Optimal (for cultivated plants) Addition of Arable Soil Layer: The Third Delegate Congress of Soil Scientists. 1st Edn., Nauka, Moscow.

Doyarenko, A.G., 1963. Water Permeability of Soils and Soils as a Factor of Field Fertility. Selected Works. 1st Edn., Publishing Agricultural Literature, Moscow.

Grabovskaya, O.A., 1954. Desalinization of saline soils and solonchaks of Tajikistan. Proceedings of the Academy of Sciences of the Tajik SSR, (STS' 54), pp: $23-40$.
Kachinsky, N., 1965. Physics of the Soil. Part.1. 1st Edn., High School, Moscow, pp: 323.

Kaldybaev, S., 2014. Saline soils of Kazakhstan and their Melioration. 1st Edn., Dulat, Almaty, pp: 484.

Kalinichenko, V.P., V.K. Sharshak, O.S. Bezuglova, E.P. Ladan and E.D. Genev et al., 2011. Changes in the soils of solonetzic associations in 30 years after their reclamation with the use of moldboard plowing, deep tillage with a threetier plow and deep rotary tillage. Eurasian Soil Sci., 44: 927-938.

Korolev, A.V., 1975. Soil Processing and Fertility. 1st Edn., Lenizdat, Leningrad, pp: 133.

Kovda, V., 1946. Origin and Mode of Saline Soils. 1st Edn., USSR Academy of Sciences, Moscow, pp: 573.

Kovda, V.A., 2008. Problems of Desertification and Soil Salinization in Arid Regions of the World. 1st Edn., Nauka, Moscow.

Kuznetsov, I.V., 1979. On some criteria for evaluation of physical properties of soil. Soil Sci., 3: 81-88.

Lebedeva, M. and O. Kutovaya, 2013. Fabric of top soil horizons in aridic soils of Central Asia. Span. J. Soil Sci., 3: 148-168.

Lebedeva, M.P., M.I. Gerasimova, D.L. Golovanov and I.A. Yamnova, 2015. Extremely arid soils of the ili depression in Kazakhstan. Eurasian Soil Sci., 48: 11-26.

Lusevics, L., 1980. Seasonal changes of permanent wilting coefficient in some selected tropical soil. Common Soil Sci. Plant Analyze.

Lyubimova, I.N. and A.F. Novikova, 2016. Changes in the properties of solonetzic soil complexes in the dry steppe zone under anthropogenic impacts. Eurasian Soil Sci., 49: 581-590.

Panfilov, V.P., 1973. Physical Properties and Water Regime of Soils of Kulunda Steppe. 1st Edn., Nauka, Novosibirsk, pp: 260.

Pankova, E.I., 2004. Secondary salinization of soils in Central Asia. Proceedings of the IV Congress of the Dokuchaev Soil Science Society, (SSS' 04), Novosibirsk, pp: 471-480.

Pankova, E.I. and M.I. Gerasimova, 2012. Desert soils: Properties, pedogenic processes and classification. Arid Ecosystems, 2: 69-77.

Revut, I.B. and N.A. Sokolovskaya, 1970. Structure and composition of soil: Theses of the reports of the IV delegates to the congress of the All-Union Society of soil scientists. Almaty.

Rode, A.A., 1956. Water regime and its types. Soil Sci., 4: 104-109.

Rode, A.A., 1952. Soil Moisture. 1st Edn., Publishing house of the Academy of Sciences of the USSR, Moscow, pp: 455.

Rode, A.A., 1966. About the lowest moisture capacity. Soil Sci., 12: 43-53. 
Ryzhov, S.N. and L.N. Slesareva, 1972. Addition and structural state of a typical serozem and their agronomic significance. Soil Sci., 12: 80-91.

Saparov, A, C. Shi and T. Abduwayli, 2014. Soils of the Arid Zone of Kazakhstan: The Current State and their use. 1st Edn., Polygraphy and Service K, Almaty, pp: 440.

Seelig, B.D. and J.L. Richardson, 1991. Salinity and sodicity in North Dakota soils. Extension Service Bull.

Shishov, L.L. and E.I. Pankova, 2006. Saline Soils in Russia. 1st Edn., Academic Book, Moscow, pp: 854.
Shvartsev, S.L., 2001. The water-rock system synergy. Earth Sci. Front., 1: 36-46.

Shvartsev, S.L., 2008. Geochemistry of fresh groundwater in the main landscape zones of the earth. Geochemistry Int., 46: 1285-1398.

Sinelnikov, Y.N., 1954. On the agronomic significance of soil density. Soil Sci., 10: 50-65.

Umarov, M.U., 1974. Physical Properties of Soils in Areas of New Perspective Irrigation of the Uzbek SSR. 1st Edn., Fan, Tashkent, pp: 282. 